\title{
ARTIGO
}

CO https://doi.org/10.22481/praxisedu.v16i39.5217

\section{NUNCA NOS SONHARAM: POLÍTICAS E POÉTICAS DA RESISTÊNCIA}

\author{
THEY HAVE NEVER DREAMED OF US: POLITICS AND POETICS OF RESISTANCE
}

\author{
NUNCA NOS SOÑARON: POLÍTICAS Y POÉTICAS DE LA RESISTENCIA
}

\author{
Debora Breder \\ Universidade Católica de Petrópolis - Brasil \\ Leticia Hermont Loures Valle \\ Universidade Católica de Petrópolis - Brasil
}

Maria Paula Eppinghaus de Figueiredo

Universidade Católica de Petrópolis - Brasil

\begin{abstract}
Resumo: Este artigo propõe uma reflexão sobre a mise-en-scène do tema da educação pública no documentário Nunca me sonharam (2017), de Cacau Rhoden, protagonizado por jovens que cursam o ensino médio em escolas públicas de diferentes regiões do Brasil. Analisa-se a narrativa fílmica, em sua retórica político-estética, tanto em relação ao discurso do autor sobre a sua obra quanto em relação aos contextos sociais de produção e recepção do longa-metragem. Busca-se, a partir dessa análise relacional, apreender as possíveis tensões que revelam as lutas simbólicas pela disputa de seu significado, considerando que o documentário foi realizado no quadro do programa "Jovem de Futuro", do Instituto Unibanco, e justamente no contexto das discussões sobre a reforma do ensino médio.
\end{abstract}

Palavras-chave: Educação pública; Ensino médio. Nunca me sonharam.

\begin{abstract}
This article proposes a reflection on the "mise-en-scène" of the public education theme in the documentary Nunca me sonharam (2017), by Cacau Rhoden, starred by young people who attend public high schools in different Brazilian regions. The film narrative is analyzed in its political-aesthetic rhetoric, both in relation to the author's discourse on his work and in relation to the social contexts of production and reception of the feature film. From this relational analysis, we seek to understand the possible tensions that reveal the symbolic struggles for the dispute of its meaning, considering that the documentary was realized as a part of the "Young of the Future" program, sponsored by Unibanco Institute, and precisely in the context of the discussions about high school reform.
\end{abstract}

Keywords: Public education; High school. Nunca me sonharam.

Resumen: Este artículo propone una reflexión sobre la puesta en escena del tema de la educación pública en el documental Nunca me sonharam (2017), de Cacau Rhoden, protagonizado por jóvenes que 
asisten a la escuela secundaria en escuelas públicas de diferentes regiones de Brasil. Analizamos la narrativa fílmica, en su retórica político-estética, tanto en relación con el discurso del autor sobre su obra como en relación con los contextos sociales de producción y recepción del largometraje. A partir de este análisis relacional, buscamos aprehender las posibles tensiones que revelan las luchas simbólicas para la disputa de su significado, considerando que el documental se llevó a cabo en el marco del programa "Jovem do Futuro" del Instituto Unibanco, y en el contexto de los debates sobre la reforma de la escuela secundaria.

Palabras clave: Educación pública; Escuela secundaria. Nunca me sonharam.

\section{Introdução}

Os pontos, os nós, os focos de resistência disseminam-se com mais ou menos densidade no tempo e no espaço, às vezes provocando o levante de grupos ou indivíduos de maneira definitiva, inflamando certos pontos do corpo, certos momentos da vida, certos tipos de comportamento.

Michel Foucault

Tudo o que os realizadores põem nos filmes e que nós não vemos. Tudo o que eles não põem nos filmes, mas que nós vemos.

Jean-Claude Carrière

Tela escura. Escutamos o som ambiente de uma escola, com sua indefectível sineta.

Na tela, vemos o Artigo 205 da Constituição Federal de 1988: “A educação, direito de todos e dever do Estado e da família, será promovida e incentivada com a colaboração da sociedade, visando ao pleno desenvolvimento da pessoa, seu preparo para o exercício da cidadania e sua qualificação para o trabalho" (BRASIL, 1990).

Corte seco: mar, zona sul do Rio, trem, subúrbio, arranha céus, campinho de futebol, cerrado, porto...

As primeiras cenas do longa-metragem Nunca me sonharam (2017), de Cacau Rhoden, apresentam múltiplas imagens do Brasil. Nelas vemos jovens - os protagonistas do filme. Realidades distintas em diferentes cenários que acabam por se encontrar, sutilmente, nas piruetas em câmera lenta dos jovens que dançam no parque, nos malabares do artista de rua, nos passos de balé de uma menina, nos passes de basquete, nos passes e passos nas ruas... Filmado em escolas públicas espalhadas por diversas regiões do Brasil, o documentário procura ecoar, em sua multiplicidade de vozes, os problemas e anseios dos estudantes do ensino médio: 
as dificuldades econômicas, os desafios enfrentados em suas trajetórias escolares, os sentidos atribuídos à educação, as expectativas em relação ao futuro...

"Eu não queria ser jovem não. Queria passar direto para a fase adulta".

"Eu sou um defeito de fábrica. Eu acho que sou assim, diferente de todo mundo".

"A única certeza que eu tenho é que um dia eu vou morrer, então tenho que fazer tudo o que eu quiser enquanto ainda tenho essa oportunidade que é respirar e viver".

"A partir do momento em que o sonho foi tirado de mim, daí eu desisti dele também".

As sequências iniciais já trazem algumas falas, em off, que vão ditando o ritmo do filme. Os relatos são potentes e envolvem o espectador na narrativa. A trilha sonora, com música instrumental e emotiva, é onipresente, desde os créditos iniciais, não permitindo o tempo, o vazio, o silêncio. Após ouvirmos mais uma fala - "eu quero que você saia do seu mundinho e cresça" -, o título do filme aparece e a câmera avança em zoom in, seguindo em frente e adentrando aos poucos na pluralidade de pés que caminham em um corredor escolar. O título vai então desaparecendo: primeiro o "Nunca me" e, por último, "sonharam", ligeiramente desfocado, permanecendo na tela poucos segundos a mais. Suas letras vão se afastando e ficando mais e mais desfocadas, sugerindo, por um lado, a multiplicidade de sonhos e a força do sonhar e, por outro, a força eminente que também pode dissipar esses sonhos. Fade out. Inserida na cidade, na sociedade, entra em cena, então, a escola - o espaço de reflexão do documentário.

"Eu acho o pessimismo um pouco reacionário. É claro que a realidade é muito cruel, mas acho injusto que a gente não mostre que existe esperança", nos revelaria o diretor em uma entrevista concedida em setembro de 2018: "Eu acho que o Brasil tem jeito, eu acredito plenamente que com força e, sobretudo, com educação, a gente consegue mudar essa realidade".

O documentário começou a ser rodado durante as manifestações estudantis de 2016 que resultaram na ocupação de mais de 1.100 instituições de ensino, entre escolas e universidades, em protesto contra o lançamento, pelo Ministério da Educação do governo de Michel Temer, da MP 746/2016 ${ }^{1}$, propondo a reforma do Ensino Médio, e contra a tramitação da PEC $241,{ }^{2}$ suspendendo por 20 anos o investimento em saúde e educação. Segundo o diretor um de seus objetivos, na época,

\footnotetext{
${ }^{1}$ Sancionada em 16/02/2017 com 147 emendas na sua redação original como Lei ${ }^{\circ} 13.415$, a chamada lei do Novo Ensino Médio tramitou em ritmo acelerado e foi aprovada pela Câmara dos Deputados e pelo Senado em um prazo de apenas seis meses, em 16/02/2017 com 147 emendas na sua redação original. O Novo Ensino Médio impõe mudanças curriculares importantes, na forma de avaliação e na carga horária. $C f$. CARDOSO DA MOTTA, Vânia \& FRIGOTTO, Gaudêncio (2017).

2 A PEC 241 (Proposta de Emenda Constitucional) em sua tramitação na Câmara dos Deputados se transformou em PEC 55, no Senado, e foi promulgada como Emenda Constitucional 95 em 15/12/16.
} 
teria sido filmar as ocupações; contudo, à medida que a equipe ia chegando nas escolas selecionadas para as filmagens, estas iam sendo desocupadas:

Quando eu saí a campo para filmar as ocupações também, por uma força do destino, em toda cidade que eu chegava, desocupava. Comecei a ficar louco, eu falei "eu não estou acreditando nisso". E chegou uma hora que aceitei que no fundo, no fundo, o que motivou os jovens a ocuparem as escolas está absolutamente no discurso deles [no filme] (RHODEN, Cacau. Entrevista concedida a Maria Paula E. de Figueiredo em 20/09/2018).

Para o cineasta, as ocupações seriam "sintomáticas" de um desejo de mudança por parte dos jovens. Desejo este que contrariaria, pelo seu ponto de vista, o senso comum acerca de uma certa juventude brasileira - um "estereótipo muito negativo" de jovens, "sobretudo das classes menos favorecidas", desinteressados pelas questões políticas e sociais. "Os jovens querem educação, querem educação de qualidade e querem transformar a sociedade positivamente", afirmaria o diretor. Em sua avaliação, embora não tenha conseguido filmar as ocupações, esse desejo de mudança por parte dos jovens estaria presente na narrativa fílmica:

O que motivou as ocupações está absolutamente explícito na narrativa e foi muito emocionante fazer esse filme. Eu posso dizer para você que eu saí pelo Brasil uma pessoa e voltei outra. E para mim foi muito difícil, sobretudo num momento de golpe. A gente sai logo após o golpe para viajar (...) e, seis meses depois, o ministro da Educação, junto com a sua equipe propõe uma reforma do Ensino Médio que é ultrajante, que é nefasta, em todos os aspectos, mas, sobretudo, nebulosa (RHODEN, Cacau. Entrevista concedida a Maria Paula E. de Figueiredo em 20/09/2018).

Ultrajante e nefasta. De fato, a reforma do ensino médio enquadra-se em uma política que promove a reprodução das hierarquias sociais. Como notam diversos autores (LIBÂNEO, 2012; FRIGOTTO, 2010), fruto de uma política educacional adotada durante o período de ditadura civil-militar-empresarial, ampliada no contexto das políticas neoliberais dos anos 1980 e 1990 e expandida no decorrer do processo de globalização, a Educação no Brasil foi direcionada para a preparação de recursos humanos para a produção. Uma política educacional que teve como efeito a deterioração da escola pública, a submissão de nossas diretrizes às políticas internacionais e a mercantilização da educação em prol do empresariado do setor. Ou seja, constituída e constituinte de relações sociais desiguais e ligada aos interesses de classe e da divisão social do trabalho, a educação, nesse contexto, visa habilitar os trabalhadores técnica, social e ideologicamente para o trabalho. 
"Por isso que a gente falou de meritocracia. Eu sou absolutamente a favor de cotas", explicaria o diretor referindo-se à intenção inicial de filmar as ocupações contra a reforma do ensino médio. De seu ponto de vista, o documentário constituiria um filme em defesa da escola pública: "esse é um filme de lutas e de causas".

Neste artigo propomos uma reflexão sobre a mise-en-scène do tema da educação pública no documentário Nunca me sonharam. ${ }^{3}$ Analisamos a narrativa fílmica, em sua retórica político-estética, tanto em relação ao discurso do autor sobre a sua obra quanto em relação aos contextos sociais de produção e recepção do longa-metragem. Buscamos, a partir dessa análise relacional, apreender as possíveis tensões que revelam as lutas simbólicas pela disputa de seu significado, considerando que o documentário foi realizado no quadro do programa "Jovem de Futuro", do Instituto Unibanco, e justamente no contexto das discussões sobre a reforma do ensino médio.

Ao analisarmos a colocação em cena deste tema no documentário, convém esclarecer que partimos de uma perspectiva teórica-metodológica que considera que toda mise-en-scène cinematográfica constitui também, antropologicamente, uma mise-en-scène das relações sociais e simbólicas que configuram o mundo (BREDER, 2015; PEÑA, 2014). É justamente a partir dessa perspectiva que os elementos internos ao filme nos interessam: quando pensados em relação aos elementos considerados externos e que, não obstante, também lhe são intrínsecos, pois conformam a obra como um produto de discursos e práticas sociais que implicam - da decupagem à montagem - uma determinada cosmologia. ${ }^{4}$ Nessa ótica todo filme pode ser considerado como material etnográfico; ou seja, como um artefato cultural que carrega em si uma determinada visão de mundo:

Os filmes, tanto de ficção como não ficcionais, desde o cinema de autor até filmes de entretenimento, podem ser tratados como documentos etnográficos na medida em que remetem, invariavelmente, a estilos de vida, hábitos e costumes, formas de linguagem, ideologias, cosmologias e mitologias de uma

\footnotetext{
${ }^{3}$ A mise-en-scène, termo francês que significa "colocação em cena", diz respeito à relação entre os elementos que compõem um filme: atores, figurino, cenário, luz, enquadramento, movimento de câmera, etc.

${ }^{4}$ Como notou o cineasta Jorge Sanjinés ao analisar sua experiência filmando com os Aymará, na Bolívia, os usos e sentidos atribuídos, por exemplo, ao primeiro-plano e ao plano sequência na composição da narrativa fílmica nessa sociedade tradicional, de ideologia holista, era diferente aos atribuídos nas sociedades ocidentais modernas, de ideologia individualista: "Os grandes autores clássicos europeus utilizam esse recurso [o primeiro plano] com grande maestria, desenvolvendo e descobrindo todas as suas notáveis possibilidades. Fazem isso com toda propriedade e talento, com toda coerência cultural e ideológica" (SANJINÉS apud AVELLAR, 1995, p. 243-5, tradução nossa). Já na cosmovisão aymara essa lógica narrativa careceria de sentido: para adquirir significado nos filmes, concebidos e interpretados pelos próprios Aymara, o primeiro-plano de um de seus membros deveria ser precedido por vários planos-sequência apresentando, antes, o grupo em sua terra, o que facultaria uma continuidade cênica menos fragmentada e mais de acordo com a própria concepção aymara de pessoa.
} 
sociedade e de uma época histórica. Eles não apenas apresentam e representam o estado da cultura, capturando-as e fixando-as num dado momento, como também as constroem e inventam, a idealizam e caricaturizam, as projetam no futuro e as legitimam [...]". (PEÑA, 2014, p. 23-24. Tradução nossa). ${ }^{5}$

É nessa perspectiva, pois, que propomos uma reflexão sobre a mise-en-scène do tema da educação pública em Nunca me sonharam - pensando de que forma esta é colocada em discurso cinematográfico no atual contexto social, no qual acirram-se as lutas simbólicas pela disputa de seu significado. Para tanto, organizamos o artigo em três partes. Na primeira, empreendemos uma descrição da estrutura narrativa do filme, considerando os elementos formais que a sustentam, tais como enquadramentos, movimentos de câmera, banda sonora, etc. $\mathrm{Na}$ segunda parte analisamos, em uma perspectiva relacional, o discurso do autor sobre a sua obra e os contextos sociais de produção e recepção do longa-metragem. Por fim, na terceira parte do artigo enquadramos uma sequência específica - justamente aquela que dá nome ao documentário - e propomos uma interpretação, entre tantas outras possíveis, partindo do princípio de que todo filme excede seu conteúdo, inevitavelmente, posto que as imagens transbordam da tela, animam o imaginário e projetam outros mundos possíveis (BREDER \& COELHO, 2017, p. 1499).

\section{A narrativa fílmica: uma descrição}

Nunca me sonharam está estruturado em sete blocos narrativos. Divididos por fades em preto e branco, eles nos guiam no emaranhado de relatos - de jovens, professores e especialistas de diversos campos (antropólogos, psicólogos, economistas, entre outros) - que delineiam um retrato complexo das juventudes e da educação pública no Brasil.

$\mathrm{O}$ primeiro bloco, Tempestade e Trovão, alude à intensidade e aos conflitos da adolescência que, intensos como uma tempestade, desencadeiam uma espécie de raio, ligando dois mundos, dois elementos - o ar e a terra. Não existe uma juventude, mas juventudes, no plural. Os jovens expressam suas ideias sobre o que é ser jovem, como lidam com suas expectativas e o que esperam da vida. Filmados geralmente em planos próximos, em contra

\footnotetext{
5 "Los filmes, tanto de ficción como de no ficción, desde el cine de autor hasta el de entretenimento, pueden ser tratados como documentos etnográficos em la medida que remiten invariablemente a estilos de vida, hábitos y costumbres, formas de lenguage, ideologías, cosmologías y mitologías de una sociedade y de una época histórica. Ellos no solo presentan o representan el estado de las culturas, capturandolas y fijándolas en un momento dado, sino que tambien las construyen y inventan, las idealizan y las caricaturizan, las proyectan al futuro y las legitiman $[\ldots] "$.
} 
plongée, eles vão revelando suas angústias e incertezas. Jovens que vão mudando à medida que se descobrem, como diz Maria Lucia Mattos (15 anos, Belém - PA): “com 15 anos, você quer ser advogado; com 16, você quer viajar o mundo. Tu muda de gosto muito rápido, tu muda de pensamento muito rápido". O ensino médio não é apenas um momento, uma transição, uma passagem, mas algo maior, mais estrutural e estruturante: é um rito de passagem, como afirma o professor indígena Gersen Baniwa. Para ele, não existe rito de passagem "sem sofrimento, sem dor". A montagem alterna os depoimentos dos jovens com imagens que contrapõem dia e noite, amanhecer e entardecer. O uso da câmera lenta, tanto no movimento dos jovens como nos travellings em favelas, busca prolongar um momento que deve ser observado e sentido pelo espectador.

“O pobre, o favelado, o negro, ele está no banco de reservas, cara. E só quem vai te colocar no jogo é estudo e leitura". A fala do redator Felipe Silva faz, então, a ponte para o próximo bloco, A Chave. A chave para um país mais justo, com oportunidades mais equitativas, seria a educação - que abre novas portas, novas visões: "E quando você chega num lugar onde você pode ter essa chave para abrir as portas é algo assustador, porque é um poder que você tem", ressalta a estudante Ana Karoline de Melo (18 anos, Teresina - PI). Mais breve que a anterior, essa parte inicia com depoimentos que versam sobre a importância da educação e encerra abordando problemas da escola pública. É o contraponto entre o sonho e a realidade. Segundo dados do Pnad - IBGE 2016, 82\% das crianças e jovens até 19 anos que estão estudando no Brasil são atendidos pela escola pública, um dado que "não é trivial”, como lembra a pedagoga Bernadete Gatti no filme. Mas "esses governantes, essas pessoas que estão no poder, eles não tiveram filhos estudando em escola pública, então, acho que há um descaso enorme com as instituições públicas”, afirma Felipe Lima (17 anos, Nova Olinda - CE).

O terceiro bloco, Nunca me sonharam, confronta os caminhos que levam à escola e que a escola pode abrir para seus alunos aos descaminhos do ensino público no país. Logo na abertura, vemos o título surgir acompanhado da pungente música instrumental. Entretanto, ao contrário do que ocorre no início do documentário, o efeito de fade out vai apagando primeiro o "sonharam" para depois apagar o "nunca", da direita para a esquerda. Nunca. O advérbio da desilusão. O indicativo de um sonho roubado. Esse bloco aborda o abandono dos estudos, seja por gravidez, violência ou falta de perspectiva; a discriminação das minorias dentro da escola; e, ao mesmo tempo, o refúgio escolar para aqueles que convivem com o assédio dentro de casa. Em um determinado momento, o contra plongée de uma casa humilde em uma área com chão de terra batido - ao som de um sino e do vento, que esvoaça suavemente a cortina de um casebre 
-, abre a sequência que dá nome ao filme. A música cresce, o estudante Felipe Lima entra em quadro. Enquanto escutamos seu depoimento em off, o vemos saindo de sua casa, na zona rural, pegando sua bicicleta e pedalando em uma estrada de terra. Um caminho árido, construído por detalhes dos pés que pedalam, do rosto que observa, das mãos que freiam, da sombra que o acompanha. Quando desce da bicicleta, ainda longe do colégio, o estudante sobe na traseira de uma pick up, onde já estão outros jovens uniformizados, para poder continuar seu caminho até a escola. Nunca me sonharam termina com depoimentos sobre a precarização da escola pública - ilustrada imageticamente por estruturas depredadas, salas abandonadas, com cadeiras empilhadas, pichadas e sujas.

A seguir, Grades correlaciona as grades de um portão - que remete a uma prisão - com a grade curricular. Imagens de portões trancados e janelas gradeadas se juntam a depoimentos de jovens e professores que apresentam uma escola presa em sua estrutura, em um modelo ultrapassado de educação, que acorrenta os alunos em horários, espaços fechados e conteúdos que não dialogam com seus interesses e suas experiências na sociedade contemporânea. "Eu acho que a escola está aí querendo formar cidadãos alienados, que não questionam o que a gente está vivendo", reclama Milena Araújo (16 anos, Serra - ES). Os jovens expõem sua insatisfação com um ambiente que não os escuta; onde se sentem encarcerados em conteúdos desvinculados da vida. No detalhe da caneta que escreve na lousa, no reflexo no quadro do docente em aula e na imagem desfocada do professor em sua cadeira, contrastando com as imagens de alunos em foco, Grades introduz então a questão da má formação dos professores, que, muitas vezes, não estão preparados para trabalhar com adolescentes e que se concentram apenas em um conteúdo a transmitir. O descaso dos governantes com a educação pública também é abordado, mas en passant, sem aprofundamento de suas raízes históricas.

Utopia, o quinto bloco narrativo, apresenta a ideia de que a melhoria da qualidade de ensino no Brasil não é impossível. O filme assume a partir de então uma visão mais otimista, com cenas de escolas bem cuidadas, claras, com jovens sorridentes pelos corredores, intercaladas por depoimentos de docentes e discentes contando sobre experiências positivas. $\mathrm{O}$ tema da "gestão" é levantado, mas fica, por assim dizer, pairando no ar, sem aprofundamento. Ao apresentar experiências bem sucedidas, Utopia mostra que uma escola atraente para seus alunos é capaz de diminuir o êxodo escolar - como o de Francisco Ronildo da Silva (18 anos, Campos Sales - CE), que teve a história contada através do depoimento de sua mãe e da leitura de uma carta enviada pelo colégio pedindo a sua volta. Com enquadramentos que detalham uma casa simples - panela sobre o fogão, banquinho no corredor, retratos na parede, e cenas do 
exterior, chão de terra batida, sendo varrido, poeira ao vento -, Ronildo e sua mãe relembram o dia em que receberam a visita dos professores e a carta: "Eu não esperava. Me surpreendeu mais ainda a assinatura de alguns colegas meus abaixo da carta. Isso foi o que me deixou bem feliz por conta de demonstrarem preocupação". A música instrumental volta a crescer com a imagem de Ronildo, olhar triste, caminhando uniformizado em direção à escola, na rua empoeirada, passando ao largo de um terreno com lixo e animais. Entre close ups e salas de aula, ouvimos mais uma vez Felipe Lima: “os professores acreditaram em mim até o último momento, me ajudaram a acreditar e a sonhar. E isso me ajudou também a refletir sobre as minhas condições, onde eu estava e onde eu poderia chegar".

Orquestra, a penúltima parte, aprofunda a discussão sobre a relação entre professores e alunos, ressaltando a necessidade de uma mudança na educação pública, o que ocorreria pelo trabalho em conjunto de alunos, professores, família e sociedade em geral. Expõe-se a necessidade de compreensão das juventudes atuais que têm esperado uma mudança na educação, uma alusão implícita ao movimento de ocupações das escolas. Uma nova prática educativa é uma responsabilidade de todos e deve ser também resultado de um trabalho coletivo, como diz a professora Luciana Sousa (Santarém, PA), cuja fala dá nome ao bloco: “E todos têm que colaborar para essa gestão, né? É um maestro, você tem que saber gerir a orquestra, um líder extremamente sensível, e o ouvido tem que estar atento a tudo. E trabalhar em harmonia, porque uma orquestra sem ser harmônica...”. Questão de gestão...

Por fim, Tâmaras remete à ideia de uma semente que é plantada no presente, mas cujo fruto será colhido no futuro. Em tom otimista, com imagens mais claras e muitos closes, o final do documentário põe em cena a esperança. Depoimentos de docentes que acreditam em uma sociedade mais igualitária são seguidos por relatos de jovens, com seus objetivos e sonhos. Em cenas breves, mais curtas do que no restante do filme, com depoimentos em close ou primeiro plano, eles vão dizendo o que esperam do futuro. A trilha sonora acompanha as imagens, com jovens em cenas diversas, pés caminhando, uma jovem afirmando, convicta: "Eu quero conhecer tudo". Os sonhos de cada um vão sendo desfiados enquanto a tela escurece e surgem os créditos finais. Em off, ouvimos "policial”, "cineasta", "professor", "estilista", "veterinária" e tantas outras profissões, proferidas, uma a uma, enquanto o som estridente e mais ritmado do violino nos dá uma sensação de suspense, como uma interrogação que só é respondida pelo último som do documentário: a indefectível sineta. 


\section{Contextos sociais de produção do filme: sobre estética e política}

"É impossível a gente espelhar a realidade, como autor, e não colocar uma certa subjetividade nisso. Então, eu queria que o filme fosse poético, enfim, fosse bonito", nos contaria Cacau Rhoden, prosseguindo: "eu venho da ficção, ou seja, criei uma narrativa ali que se inspira na ficção em termos de atos dramáticos, de colocar os conflitos necessários, as viradas etc., para envolver o público num assunto que deveria fazer parte da pauta cotidiana".

Ao considerarmos a declaração do diretor sobre a vontade de fazer um filme "poético", "bonito", "para envolver o público" em uma causa, é inevitável pensar na relação entre estética e política. Como nota Rancière (2005), a imposição de princípios de visão de mundo se dá a partir de uma determinada partilha do sensível, ou seja, de uma determinada ordenação social dos modos de fazer, de dizer, de dar a ver. Para o autor, a estética e a política são maneiras de organizar o sensível: de construir a visibilidade e a inteligibilidade dos acontecimentos. Se a política trata do que se vê e do que se pode dizer sobre o que é visto - ou de quem tem competência para ver e dizer -, não surpreende que seja justamente no terreno estético que hoje se forjam boa parte das estratégias políticas de (in)visibilidade.

Estratégias estéticas cujos efeitos políticos só podem ser interrogados quando, ao enfocarmos um filme, não nos limitamos à análise de seu argumento, considerando, fundamentalmente, a forma como nos é apresentado tal argumento. Por forma referimo-nos, aqui, ao que demarca a singularidade da linguagem audiovisual em relação às outras linguagens artísticas: a relação entre os planos, movimentos de câmera, montagem, banda sonora, etc. Ao considerarmos o discurso cinematográfico, trata-se de pensar o que se diz e o que se oblitera na transparência ou opacidade das imagens, como tão bem notou Xavier (1984), posto que o sentido não lhes é imanente, sendo imprescindível considerar a complexa teia de relações que conformam seus múltiplos significados.

Essas questões de ordem estética, contudo, só adquirem pleno sentido enquanto práticas sociais que revelam estratégias políticas quando consideradas em relação aos contextos sociais de produção, circulação e recepção dessas narrativas. É preciso indagar quem produz os filmes, em que condições e por que, visto que as narrativas audiovisuais são produzidas por agentes cujos diferentes capitais os posicionam em um campo constituído por relações de poder. Nesse sentido, analisar o discurso cinematográfico significa analisar, também, a posição do autor do discurso, pois essa posição configura não apenas sua intencionalidade, como também sua 
possibilidade de maior ou menor circulação. E, por conseguinte, de sua maior ou menor capacidade de impor princípios de visão de mundo.

Produzido e distribuído pela produtora Maria Farinha Filmes, Nunca me sonharam foi realizado no quadro do programa "Jovem de Futuro", do Instituto Unibanco. O argumento do filme foi escrito por Cacau Rhoden, da produtora, e por Ricardo Henriques e Tiago Borba, do Instituto Unibanco. Como explicaria o diretor,

O Instituto Unibanco já havia assistido outros filmes nossos, da Maria Farinha, porque a Maria Farinha é uma produtora que tem esse recorte conceitual de trabalhar apenas com filmes ligados a causas. Ou causas sociais, ou ambientais, ou de direito social, temas sociais, e educação. A gente tem cases de bastante sucesso em termos de comunicação mesmo, com o público (RHODEN, Cacau. Entrevista concedida a Maria Paula E. de Figueiredo em 20/09/2018).

Frisando que o Brasil seria um país que “consome muito pouco documentário", e que por conta da escassez de público estes ficariam pouco tempo em exibição nas salas de cinema, o diretor ressalta o sucesso de público alcançado por outros documentários produzidos pela Maria Farinha Filmes, como Muito além do peso (2012), de Estela Renner, sobre obesidade infantil; e Tarja Branca (2013), dirigido por ele, sobre a importância da ludicidade para a saúde física e mental. "Desde esses filmes a gente conseguiu ter um público imenso, não só no cinema, mas também na plataforma", contaria, explicando que a produtora possui uma plataforma que reúne e distribui gratuitamente "filmes ligados a causas":

Não só filmes que nós produzimos, mas filmes do mundo todo, temos filmes de Hollywood, tem ficção, tem documentário, enfim... E eles [Instituto Unibanco] estavam muito interessados em falar de um programa que se chama Jovem de futuro, que é um programa que aporta recursos nas escolas públicas, no Ensino Médio, e que dá cursos de formação, ligados à gestão, dando ferramentas ali pra esses educadores, que são as pessoas que estão no front, no dia a dia da escola pública do Brasil, para cobrar seus direitos e a formar redes de parcerias (RHODEN, Cacau. Entrevista concedida a Maria Paula E. de Figueiredo em 20/09/2018).

Segundo o site do Instituto Unibanco, o programa "Jovem de Futuro" foi lançado em 2007 “com base na premissa de que uma gestão de qualidade, eficiente, participativa e orientada 
para resultados, com equidade, pode proporcionar impacto significativo no aprendizado dos estudantes". 6

Ao considerarmos o programa é escusado dizer que assim como em outros países da América do Sul, no modelo de Educação adotado no Brasil são os grupos empresariais conjugando empresas educacionais, grupos midiáticos, instituições privadas e seus representantes políticos - que vêm ditando as regras nesse campo, arvorando-se em experts na questão. Essa coalizão entre poder público e iniciativa privada produz a crença de que, se a educação pública não vai bem, o modelo empresarial - baseado na ideia de "gestão" - é o único capaz de produzir resultados positivos. Essa forma tecnicista de encarar a Educação é uma característica do pensamento neoliberal, que propõe que questões políticas e sociais sejam solucionadas através de propostas de gestão, transformando-as em questões de ordem técnica. Como notam Gentili \& Silva (1998: 18-19), “Tudo se reduz, nessa solução, a uma questão de melhor gestão e administração e de reforma de métodos de ensino e conteúdos curriculares inadequados. Para problemas técnicos, soluções técnicas, ou melhor, soluções políticas traduzidas como técnicas". Assim, a Educação não é vista como um campo de disputas ideológicas em torno do problema da desigualdade de oportunidades e de recursos simbólicos.

Também é escusado dizer que o objetivo desse modelo educacional calcado nas políticas neoliberais é não apenas a preparação dos jovens para o mercado de trabalho, como também a difusão dos valores do credo liberal (GENTILI; SILVA, 1998). O projeto neoliberal, projeto distópico, cria um espaço social e simbólico no qual se torna inviável pensar a sociedade fora da perspectiva capitalista:

Nesse espaço hegemônico, visões alternativas e contrapostas à
liberal/capitalista são reprimidas a ponto de desaparecerem da imaginação e
do pensamento até mesmo daqueles grupos mais vitimizados pelo presente
sistema, cujos males, estranhamente, são atribuídos não ao seu núcleo
econômico - capitalista - mas ao suposto fato de que ainda não é
suficientemente capitalista. Não é irrelevante a esse processo de redefinição
das categorias com que pensamos o espaço social a tradução de questões
sociais e políticas em questões de moralidade pública, de conduta e de
assistencialismo social. Nessa redefinição a solução dessas questões é, além

6 "Lançado em 2007, o programa JF foi estruturado com base na premissa de que uma gestão de qualidade, eficiente, participativa e orientada para resultados, com equidade, pode proporcionar impacto significativo no aprendizado dos estudantes. O Jovem de Futuro, por meio de parceria com as secretarias estaduais de Educação, oferece diferentes instrumentos que dão suporte ao trabalho de gestão das escolas e das redes de ensino, como assessoria técnica, formações, análises de dados e o apoio de sistemas tecnológicos especialmente desenvolvidos para ele. O programa também estimula as trocas de experiências entre os gestores nele envolvidos, de forma a contribuir ao fortalecimento dos conhecimentos instalados e produzidos em cada rede parceira". Disponível em: https://www.institutounibanco.org.br/jovem-de-futuro. Acesso em 18/11/2018. 
disso, deslocada do espaço público, social e político e é re-situada no âmbito da iniciativa individual (SILVA, 1998, p. 13-14).

Nesse processo de desinvestimento do espaço público e de exacerbação do individualismo, noções como as de justiça social, igualdade e bem comum tendem a ficar em segundo plano, sendo substituídas por noções como as de produtividade, qualidade e eficiência como condições essenciais para conseguir-se acesso à modernidade, ao sucesso profissional e, consequentemente, à ascensão social. Não por acaso, como o próprio nome do referido programa sugere, trata-se de formar o "jovem de futuro", no singular, e não os "jovens do futuro" - a preposição, aqui, demarcando simbolicamente a relação simbiótica entre o individualismo como valor e o mercado como destino.

Ao ser questionado sobre o processo de produção do longa-metragem e sua relação com o programa do Instituto Unibanco, o diretor, contudo, foi enfático em defender sua autonomia durante o processo de produção e realização do filme:

Quando eles me convidaram para fazer o filme, a primeira coisa que eu coloquei pra eles é que eu aceitava o convite contanto que a condição é que eu tivesse total liberdade autoral, que eu respeitaria ali algumas coisas do programa deles que me interessavam como discurso, mas que seria absolutamente autoral, justamente porque a gente precisava ter um filme não institucional. Tanto é que a gente nem menciona o programa nem nada (RHODEN, Cacau. Entrevista concedida a Maria Paula E. de Figueiredo em 20/09/2018).

De fato, não há menção ao programa no filme. Tampouco há menção ao fato de que os jovens entrevistados e as escolas visitadas, em quinze cidades de oito estados, o integrassem, como revelaria o próprio Ricardo Henriques, superintendente executivo do Instituto Unibanco, coautor do argumento do filme: “A criação do filme, a busca dos personagens, a identificação de situações-problema, de gargalos a serem resolvidos e dos personagens a serem entrevistados foram todos em cima de escolas que são do Jovem de Futuro” (Agência Brasil, 27/05/2017)7. Conforme explicaria Rhoden, antes de iniciar as filmagens a equipe realizou uma longa pesquisa, que teria durado meses, aproveitando experiências que o programa já havia mapeado: "a única coisa que eles pediram, e que eu achei absolutamente coerente, é que a gente contemplasse as cinco regiões do país". Em sua perspectiva, no entanto, o discurso fílmico produzido pela edição de mais de trezentas horas filmadas - que resultaria em pouco menos de

\footnotetext{
${ }^{7}$ Disponível em: http://agenciabrasil.ebc.com.br/educacao/noticia/2017-05/documentario-traz-sonhos-e-desafiosdos-jovens-do-ensino-medio-publico. Acesso em 22/11/2018.
} 
uma hora e meia de filme - estaria absolutamente alinhado com suas próprias convicções políticas:

O discurso do filme é um discurso pró educação pública. Nesse sentido, eu sou um homem absolutamente alinhado à esquerda. Então, a minha preocupação inicial foi essa, justamente, por isso que eu me calcei nesse sentido, em ter um contrato onde eu pudesse espelhar essas narrativas dos jovens, das juventudes brasileiras, que é justamente o que eu acho que pouquíssimas vezes foi feito. (RHODEN, Cacau. Entrevista concedida a Maria Paula E. de Figueiredo em 20/09/2018).

"A intenção foi das melhores", diria o realizador, ressaltando o sucesso de crítica e público angariado pelo filme em diversos festivais, mas confessando sua contrariedade com o teor de certas apreciações veiculadas na época de seu lançamento. Se as críticas foram majoritariamente positivas - ressaltando especialmente a relevância social da questão tratada, sua capacidade em suscitar debates e a potência dos depoimentos dos jovens -, algumas, entretanto, foram desfavoráveis ao problematizar os limites, estéticos e políticos, de uma produção feita no âmbito de um programa patrocinado por uma instituição financeira.

Assim, em uma matéria publicada em junho de 2017, um crítico avaliava que não obstante a relevância do tema, o filme não se "sustenta como cinema":

"Nunca me sonharam" é um documentário sobre um assunto sério e relevante. Entretanto, sua estética, sua trilha sonora onipresente, entre outras coisas, o fazem parecer uma espécie de reclame para ser exibido, em partes, no intervalo de algum telejornal do horário nobre. Em suas intenções e visual, lembra muito uma série institucional produzida pelo antigo banco Bamerindus veiculada nos intervalos do Jornal Nacional, aos sábados, chamado "Gente que faz", sobre pessoas comuns e seus grandes feitos. Já este filme poderia ser chamado de "Gente que estuda" e é patrocinado pelo Instituto Unibanco (Alysson Oliveira, do Cineweb - Reuters Brasil, 07/06/2017)

Uma das apreciações mais contundentes, contudo, partiria não da crítica especializada, mas do próprio campo da educação. Em "Nunca me sonharam e o sequestro das histórias", publicada em setembro de 2017 na Carta Educação, Fernando Cássio, professor da Universidade Federal do ABC, defendia que o documentário - exibido no seminário "Desafios Curriculares do Ensino Médio: flexibilização e implementação", promovido pelo Instituto Unibanco em Junho de 2017 -, constituiria uma peça de propaganda para a reforma do ensino médio, salientando seu uso político, durante o evento, pelos maiores interessados na reforma:

Participaram do evento todos os interessados na Reforma do Ensino Médio: Governo Federal, gestores de redes estaduais, institutos e fundações 
empresariais, Conselho Nacional de Educação, sistema S, editores de materiais didáticos. O "documentário" foi exibido em sessão especial durante o Seminário, mas também projetado no saguão e citado inúmeras vezes como justificativa para a Reforma do Ensino Médio nos moldes propostos pelo Instituto Unibanco. Apoiado no know-how de seus projetos e parcerias e na narrativa do longa, o economista Ricardo Henriques, superintendenteexecutivo do Instituto Unibanco, e que coassina o argumento de Nunca me Sonharam, insiste naquilo que tem denominado "sequestro dos sonhos dos jovens" (Fernando Cássio, Carta Educação, 06/09/2017)

Reconhecendo a potência dos depoimentos dos jovens, que comoveria e envolveria o espectador, Cássio destacava, no entanto, que junto a outras fundações empresariais, o Instituto vinha promovendo encontros focais com jovens e adultos visando sondar a resistência de docentes e discentes à reforma. Conforme frisava em sua crítica, as soluções propostas por esses institutos e fundações, calcadas no neoliberalismo, não passam evidentemente pelo fortalecimento do papel do Estado na garantia do direito à Educação. Em sua perspectiva, o filme replicaria a mesma lógica defendida por aqueles que o patrocinaram:

Se o Estado não possui um projeto para a educação, é a sociedade que deve se mobilizar para transformá-la: essa é a tese de todos os projetos neoliberais para a educação e é a tese do Instituto Unibanco, como é também a tese do filme que ele patrocina e a tese que os depoimentos nele contidos são convocados a defender (...). Currículos flexíveis, habilidades socioemocionais, importação de modelos estrangeiros e privatização da gestão escolar são as soluções apresentadas por Instituto Unibanco e Instituto Ayrton Senna, mas também pelo Banco Mundial, pelo Banco Interamericano de Desenvolvimento (o BID) e pela Organização para a Cooperação e Desenvolvimento Econômico (a OCDE, que produz o ranking educacional conhecido como Pisa) - todos devidamente representados no evento do Unibanco e comovidos pelos depoimentos de Nunca me Sonharam (Fernando Cássio, Carta Educação, 06/09/2017).

“Quem é que sequestra os sonhos dos jovens?", interrogaria o autor ao finalizar sua apreciação crítica da obra.

"Filme de autor ou de um banco?", indagaria, por sua vez, o professor Aristóteles Berino no blog Pedagogia da Imagem. ${ }^{8}$ Avaliando positivamente o fato de o documentário ter privilegiado o depoimento dos jovens, mostrando "com transparência" tanto as condições sociais em que vivem nas periferias quanto suas formas criativas de resistência, o autor questionaria, entretanto, o sentido do silenciamento de questões fundamentais - como as ocupações e a reforma do ensino médio. De seu ponto de vista, o filme apresentaria uma

\footnotetext{
${ }^{8}$ Disponível em http://aristotelesberino.blogspot.com/2017/06/nunca-me-sonharam.html. Acesso em 22/11/2018.
} 
“inegável abordagem crítica" das desigualdades sociais, mas cujos propósitos e efeitos seriam limitados por não questionar politicamente a raiz do problema:

No entanto, a suposição de uma educação "democrática" ou "liberal" não é suficiente para contestar a situação da escola destinada à maioria popular no Brasil. É preciso ser radical também no cinema, ou seja, ir à fronteira política do problema. Nunca Me Sonharam em momento algum coloca de maneira objetiva o problema da finalística na educação. Sobre isso, observa inequivocamente Paulo Freire: "A questão fundamental é política. Tem que ver com: que conteúdos ensinar, a quem, a favor de quê, de quem, contra quê, contra quem, como ensinar". Ou seja, se a escola precisa mudar, é preciso discutir também, contra quê, para quê, em favor de quem, contra quem. Se um filme sobre juventudes e educação, que pretende ser crítico, não expõe isso claramente... (Aristóteles Berino, Blog Pedagogia da Imagem).

O autor finalizaria sua crítica observando que o documentário seria exibido, "em destaque", durante o evento "Desafios Curriculares do Ensino Médio: a implementação da flexibilização". À pergunta "filme de autor ou de um banco?", Berilo concluiria: "Entre as tessituras do visível e do invisível um filme expõe a sua imagem da política e a sua política da imagem".

O diretor, por sua vez, refutaria veemente as acusações de que Nunca me sonharam constituiria um instrumento para a "privatização do ensino público no país", enfatizando a presença, no documentário, de educadores e outros especialistas engajados na defesa da educação pública: “O filme fala por si, não é uma marca que está falando, não é um banco que está falando, porque se não você desqualifica todas as pessoas que estão ali, como se aquelas pessoas fossem instrumentos de manipulação... E não são”.

\section{O filme fala por si?}

Um filme fala por si? Interrogar os contextos sociais de produção de um filme conduz à problematização, também, dos contextos sociais de sua recepção; ou seja, dos processos sociais de apropriação das narrativas audiovisuais segundo a ótica do espectador. Esses processos, como sabemos, não são nunca inteiramente passivos e isentos de contradições: os deslizamentos de sentido são inevitáveis, pois a distância entre o que dizem as narrativas audiovisuais e o que efetivamente nelas se vê é preenchida pela própria experiência dos sujeitos em questão.

Considerando, pois, que o ponto de vista do espectador também produz o significado, gostaríamos de retornar à sequência que dá nome ao filme, protagonizada pelo jovem Felipe 
Lima. Enquanto o vemos saindo de sua casa, na zona rural, pegando sua bicicleta e pedalando em uma estrada de terra, escutamos seu relato em off:

Como meus pais não foram bem-sucedidos na vida, eles também não me influenciavam, não me davam força para estudar. Achavam que quem entrava numa universidade era filho de rico. Acho que eles não acreditavam que um pobre também pudesse ter conhecimento, pudesse ser inteligente, sabe? Para eles, o máximo era terminar o Ensino Médio e arrumar emprego, trabalhar em roça, tipo vendedor ou alguma coisa do tipo. Acho que nunca me sonharam sendo um psicólogo, nunca me sonharam sendo um professor, nunca me sonharam sendo um médico. Eles não sonhavam e não me ensinaram a sonhar. Eu aprendi a sonhar sozinho (Felipe de Lima, 17 anos, Nova Olinda - CE).

"Eu aprendi a sonhar sozinho"... Nem a música, onipresente sequência após sequência ao longo do filme - impedindo o silêncio, a percepção do tempo, a reflexão -, consegue obliterar a potência de seu relato. Um relato que demonstra dolorosamente, em sua autorreflexividade e extraordinária capacidade sintética, o quanto as esperanças subjetivas estão intrinsecamente relacionadas às condições objetivas de existência (BOURDIEU, 2010: 47). Com efeito, se as aspirações dos pais de Felipe em relação ao próprio filho não incluíam vê-lo ingressar em uma universidade, é tão somente porque as condições objetivas de existência de seu grupo social de origem sempre atestaram, histórica e socialmente, ser esta uma possibilidade senão impossível, ao menos bastante improvável - afinal de contas, "quem entrava numa universidade era filho de rico". As famílias, geralmente, pensam e planejam o que é possível de acordo com seu habitus de classe: o "destino" de seus membros é considerado como mais ou menos factível segundo as experiências vividas de êxitos e fracassos - um cálculo inconsciente baseado no senso prático. Para os pais de Felipe, lavradores com pouca escolaridade, que não investiram na educação formal por não vislumbrem chances de ascensão social por meio do êxito escolar, ter um filho médico, professor ou psicólogo não estava no horizonte dos possíveis. Por isso, Felipe diz que sonha sozinho...

Mas Felipe “diz” mais. Seu relato é um testemunho da violência simbólica - violência cuja eficácia é tanto maior quanto mais invisível o seu exercício; violência cujo exercício requer o consentimento inconsciente de suas vítimas, isto é, o seu não reconhecimento como violência... (BOURDIEU, 2002: 45 et seq.). Assim, ao falar de seus pais - que "não foram bem sucedidos na vida" - Felipe revela o quanto a estrutura social profundamente desigual que conforma a sociedade brasileira faz com que os mais despossuídos econômica e culturalmente atribuam a si, ou aos seus, a responsabilidade pela exclusão: o malogro é de seus pais - questão de ser bem ou mal sucedido na vida - e não da sociedade brasileira - marcada por uma extrema 
desigualdade social. Sua observação - "Acho que eles não acreditavam que um pobre também pudesse ter conhecimento, pudesse ser inteligente, sabe?" - ilustra à perfeição o fato de que a privação da posse, em matéria de cultura, exclui a própria consciência de sua privação:

Instrumento privilegiado da sociodicéia burguesa que confere aos privilegiados o privilégio supremo de não parecer como privilegiados, ele consegue tanto mais facilmente convencer os deserdados que eles devem seu destino escolar e social à sua ausência de dons ou de méritos, quanto em matéria de cultura a absoluta privação de posse exclui a consciência da privação de posse. (BOURDIEU; PASSERON, 1992: 218).

Como nota Bourdieu (2015a: 248-250), ao exigir implicitamente o que não fornece explicitamente, a escola exerce a violência simbólica sobre os alunos mais desprovidos de capital cultural - sobretudo o linguístico - levando à eliminação branda. São os excluídos do interior, aqueles jovens, por assim dizer, "esquecidos" na escola e destinados a ocupar as funções de menor prestígio no mercado de trabalho: afinal de contas, "nunca me sonharam", como diria Felipe. O pronome usado pelo estudante na frase que dá título ao documentário se pluraliza na sociedade brasileira: "nunca nos sonharam" poderiam dizer em uníssono tantos jovens que, como ele, não têm grandes expectativas em relação ao futuro posto que trazem consigo um legado de exclusão.

Uma exclusão que é tematizada, no filme, por meio de seu combate a partir de pequenas ações individuais, como a ajuda da bibliotecária que leva almoço para Felipe, a dedicação dos professores, a força para acreditar além da expectativa dos pais, o sonhar sozinho. Ao mergulharmos na complexa teia de imagens e relatos de Nunca me sonharam, percebemos que o discurso implícito do filme nos diz que são as atitudes individuais que fazem a diferença: seriam a perseverança e as atitudes de professores e alunos que transformariam a educação junto, evidentemente, à ideia de uma "boa gestão". Assim, o filme elude a questão central, que é política e diz respeito às disputas ideológicas em torno do sentido da educação em um país que figura entre os mais desiguais do mundo, no qual apenas $1 \%$ da população concentra quase $30 \%$ da renda nacional (SOUZA, 2016). Os longos e lentos travellings pelas favelas e periferias mostram a pobreza, mas não a problematizam em suas estruturas históricas e sociais, nem ao sistema que a promove e dela se serve.

Filmado em um período de ocupações em escolas de todo o país e protestos contra uma reforma do ensino médio aprovada às pressas, sem maiores discussões, as críticas de estudantes e professores ao projeto não foram enfocadas no documentário. O curioso é que o próprio 
diretor afirmaria não ter encontrado, em suas viagens Brasil afora produzindo o longametragem, quem a defendesse:

[Quando eles falam que] Setenta por cento dos jovens brasileiros apoiam a reforma do ensino médio, eu queria saber quem são esses $70 \%$, porque viajando o Brasil inteiro, não encontrei um, não encontrei um educador, não encontrei um jovem que apoie uma barbaridade dessa. (RHODEN, Cacau. Entrevista concedida a Maria Paula E. de Figueiredo em 20/09/2018).

Essas vozes, contudo, não reverberam no documentário.

Com mais de trezentas horas de material para ser editado, muitas imagens e depoimentos evidentemente teriam que ser cortados, como nos explicaria o diretor: "o documentário é um organismo vivo, à medida que você vai fazendo as histórias vão mudando. E quando você vai para a montagem, mais ainda. E é claro que muito ouro fica de fora, porque não cabe". Não deixa de ser significativo, entretanto, que justo o tema mais debatido no campo da educação desde 2016 - a reforma do ensino médio - tenha ficado no fora de campo de um documentário que, tendo estudantes do ensino médio como protagonistas, se propôs a enquadrar em primeiríssimo plano o tema da educação pública no Brasil.

"É muito muito claro, e não é nem um pouco clichê o discurso do Paulo Freire dizendo, e do Darcy Ribeiro dizendo, que existe um plano de desmonte. Para mim, isso ficou claríssimo", nos contaria o diretor na mesma entrevista. No filme, no entanto, essa perspectiva crítica não entra em quadro: o plano de desmonte não é enfocado. O que percebemos do quarto bloco narrativo em diante é a colocação em cena de ações localizadas, em tom otimista, a partir da dedicação de professores e da força de vontade de jovens que conseguiram seguir adiante, apesar das adversidades, e que continuam sonhando com um futuro diferente. Voltemos a uma das falas de Felipe em outra passagem do filme: “Os professores acreditaram em mim até no último momento, me ajudaram a acreditar e a sonhar. E isso me ajudou também a refletir sobre as minhas condições, onde eu estava e onde eu poderia chegar. Eu não tinha perspectiva de vida, perspectiva de futuro". Casos isolados que nos dão esperança, de fato, mas que passam ao largo do debate das questões estruturais que dizem respeito, em última instância, às politicas públicas voltadas para a educação no quadro do neoliberalismo, que exacerba o individualismo como valor e nos concede o mercado como único destino.

O próprio diretor apresenta uma perspectiva crítica em relação à ideia de educação compreendida meramente como passagem, como preparação para o futuro: 
Se você perguntar pra maioria das pessoas... se você entrar num prédio, entrar nos andares e for perguntando de apartamento em apartamento o que é educação e pra que serve a educação, certamente, a maioria das pessoas vai te responder que a educação serve para disciplinar e para preparar para o futuro. $\mathrm{Eu}$ acho que é muito reducionista isso. (RHODEN, Cacau. Entrevista concedida a Maria Paula E. de Figueiredo em 20/09/2018).

Um futuro, ao que parece, que só pode ser imaginado em termos de mercado de trabalho: trata-se de formar o "Jovem de Futuro", como tão bem explicita o programa do Instituto Unibanco. Ideia reiterada pela última sequência do documentário, na qual os sonhos desfiados pelos jovens encontram a sua mais perfeita tradução nas profissões enumeradas em off.

Em suma, se o ponto de vista do espectador também produz o significado - ou seja, se o filme não fala por si, desvinculado de seus contextos sociais de produção, circulação e recepção -, é preciso fazer falar o filme nas salas de aula; é preciso trazer à tona tudo o que não é dito explicitamente na mise-en-scène mas permanece implícito, sugerido por preterição, quando não simplesmente obliterado. A fala de Felipe é potente: "refletir sobre as minhas condições" é o ponto de partida para o sujeito compreender-se como agente constituído por relações sociais; compreender que, se a relação precede o indivíduo (no sentido lógico, não ontológico), o “onde eu estava e onde eu poderia chegar" não depende única e exclusivamente de um querer desvinculado das condições objetivas de existência; compreender, enfim, que grande parte do sofrimento experimentado como individual ("Eu vivo praticamente sem ter certeza do que vai acontecer amanhã. Então, eu não espero muito. Eu tento planejar alguma coisa que vai acontecer na minha vida, mas eu não espero muito, sabe?"), é ressentido coletivamente e se deve a fatores sociais.

Não aprendemos a sonhar sozinhos: os sonhos também se constroem por meio de relações, como nos ensina Felipe ao falar de seus professores. A sonhar e a resistir: pois entre a agência de professores e alunos e as estruturas sociais; entre nossas esperanças subjetivas e nossas condições objetivas de existência, há sempre espaço para as lutas cognitivas a respeito do sentido do mundo, já que, como lembra Bourdieu ao final de A miséria do mundo, o que o mundo social fez, o mundo social pode desfazer (BOURDIEU, 2017: 735).

\section{Considerações finais}

Partindo do princípio de que todo filme, seja ficção ou documentário, constitui um artefato cultural e, por conseguinte, como diria Ferro (1976:06), "vale por aquilo que 
testemunha, pela abordagem sócio histórica que autoriza”, procuramos, nesse artigo, interrogar a mise-en-scène do tema da educação pública no documentário Nunca me sonharam, de Cacau Rhoden. A partir de uma análise relacional - cotejando a narrativa fílmica, em sua retórica politico-estética, tanto em relação ao discurso do autor sobre a sua obra quanto em relação aos contextos sociais de produção e recepção do longa-metragem -, buscamos apreender as tensões que revelam as lutas simbólicas pela disputa de seu significado. Como vimos, o documentário, protagonizado por jovens que cursam o ensino médio em escolas públicas de diversas regiões do Brasil, foi realizado no quadro do programa "Jovem de Futuro", do Instituto Unibanco, e justamente no contexto das discussões sobre a reforma do ensino médio.

Ao consideramos a narrativa fílmica em relação ao discurso do autor sobre a sua obra e aos contextos sociais de sua produção e recepção, foi possível perceber as tensões e contradições que revelam que, assim como o seu próprio tema de eleição - a educação -, Nunca me sonharam constitui, também, um objeto de lutas simbólicas pela disputa de seu significado. Filme em defesa da educação pública? Filme de um banco em defesa de sua privatização? Filme ou mera peça institucional?

À multiplicidade de olhares lançados sobre o filme correspondem, evidentemente, múltiplas interpretações.

Defendemos, aqui, que todo filme inevitavelmente excede seu significado: o filme não fala por si, desvinculado de seus contextos sociais de produção, circulação e recepção. Portanto, se o ponto de vista do espectador também produz o significado, precisamos fazer falar Nunca me sonharam nas salas de aula, já que as lutas simbólicas travadas em torno da recepção e apropriação das narrativas audiovisuais são capazes de gerar as mais diversas estratégias, tanto de reprodução dos discursos hegemônicos que reforçam a ordem simbólica, quanto de resistência e subversão que a interrogam, propondo novas narrativas sobre o mundo.

\section{REFERÊNCIAS}

AVELLAR, José Carlos. A ponte clandestina. Teorias de cinema na América Latina. São Paulo: Edusp, 1995.

BOEMH, Camila. Documentário traz sonhos e desafios dos jovens do ensino médio público. Agência Brasil, 27/05/2017.

BOURDIEU, Pierre \& PASSERON, Jean-Claude. A Reprodução: elementos para uma teoria do sistema de ensino. $3^{\text {a }}$ ed. Rio de Janeiro: Editora Francisco Alves, 1992. 
BOURDIEU, Pierre. A escola conservadora: as desigualdades frente à escola e à cultura. In: NOGUEIRA, Maria Alice; CATANI, Afrânio (Org.). Escritos de educação, 16 ed. Petrópolis, RJ: Vozes, 2015a.

BOURDIEU, Pierre. Os excluídos do interior. In: NOGUEIRA, Maria Alice; CATANI, Afrânio (Org.). Escritos de educação, 16 ed. Petrópolis, RJ: Vozes, 2015 b.

BOURDIEU, Pierre. A dominação masculina. $3^{\mathrm{a}}$ ed. Rio de Janeiro: Bertrand do Brasil, 2002.

BRASIL. [Constituição (1988)]. Constituição da República Federativa do Brasil: promulgada em 5 de outubro de 1988. 4. ed. São Paulo: Saraiva, 1990.

BREDER, Debora. A Zed And Two Noughts: sobre antropologia, cinema e outras maquinações. In: OLIVEIRA, Esmael; VIANA JUNIOR.; Mario; COSTA, Patrícia (Org). Metodologias de pesquisa em ciências humanas - Campos, Problemas e Objetos. Curitiba: Editora CRV, 2015, pp. 73-90.

BREDER, Debora; COELHO, Paloma. Desvelando imagens: o visível e o indizível na pele que habitamos. Estudos Feministas, Florianópolis, v. 25, nº 3, pp. 1489-1502, set.-dez., 2017.

CARDOSO DA MOTTA, Vânia; FRIGOTTO, Gaudêncio. Por que a urgência da reforma do ensino médio? medida provisória $n^{\circ}$ 746/2016 (lei n ${ }^{\circ} 13.415 / 2017$ ). Educ. Soc., Campinas, v. 38, nº. 139, pp.355-372, abr.-jun., 2017.

CARRIÈRE, Jean Claude. A linguagem secreta do cinema. Rio de Janeiro: Nova Fronteira, 1995.

CÁSSIO, Fernando. Nunca me sonharam e o sequestro das histórias. Documentário comove o público, mas é peça de propaganda de projetos de privatização da gestão escolar e para a Reforma do Ensino Médio. Carta Educação, 06 de Setembro de 2017.

FOUCAULT, Michel. História da sexualidade I: a vontade de saber. $13^{\mathrm{a}}$ ed. Rio de Janeiro: Graal, 1999.

FRIGOTTO, Gaudêncio. Educação e a crise do capitalismo real. São Paulo: Cortez, 2010.

GENTILI, Pablo A.A.; SILVA, Tomaz Tadeu da (Org.). Neoliberalismo, qualidade total e educação - Visões críticas. Petrópolis: Vozes, 1998.

LIBÂNEO, José Carlos. O dualismo perverso da escola pública brasileira: escola do conhecimento para os ricos, escola do acolhimento social para os pobres. Revista Educação e Pesquisa, São Paulo, v. 38, n. 1, p. 13-28, 2012.

PEÑA, Francisco de La. Imaginários fílmicos, cultura y subjetividade. Por un análisis antropológico del cine. México, DF: Ediciones Navarra, 2014. 
RANCIÈRE, Jacques. A partilha do sensível: estética e política. São Paulo: EXO Experimental/ Editora 34, 2005.

SOUZA, Pedro Herculano. A desigualdade vista do topo: a concentração de renda entre os ricos no Brasil, 1926-2013. Tese (Doutorado em Sociologia) - Universidade de Brasília/UnB, 2016.

XAVIER, Ismail. O discurso cinematográfico: a opacidade e a transparência. $2^{\mathrm{a}}$ ed. Rio de Janeiro: Paz e Terra, 1984.

\section{SOBRE AS AUTORAS:}

\section{Debora Breder}

Doutora em Antropologia pela Universidade Federal Fluminense com estágio-doutoral na École des Hautes Études em Sciences Sociales (EHESS). Professora do Programa de PósGraduação em Educação da Universidade Católica de Petrópolis e pesquisadora do Grupo de Estudos em Educação, Cultura e Contemporaneidade (GRECCA/UCP), do Grupo de Análises de Políticas e Poéticas Audiovisuais (GRAPPA/UERJ) e do Grupo de Reconhecimento de Universos Audiovisuais (GRUA/UFRJ). E-mail: deborabreder@hotmail.com

(iD) http://orcid.org/0000-0002-8785-4265

\section{Leticia Hermont Loures Valle}

Mestre em Educação pela Universidade Católica de Petrópolis e pesquisadora do Grupo de Estudos em Educação, Cultura e Contemporaneidade (GRECCA/UCP). E-mail: leticiahlvalle@yahoo.com.br

(iD http://orcid.org/0000-0002-5021-3640

\section{Maria Paula Eppinghaus de Figueiredo}

Mestre em Educação pela Universidade Católica de Petrópolis e pesquisadora do Grupo de Estudos em Educação, Cultura e Contemporaneidade (GRECCA/UCP). E-mail: paulaeppinghaus@hotmail.com

(iD http://orcid.org/0000-0002-8372-6741 